\title{
A (des)construção do "herói" nos discursos sobre o mensalão: o caso Joaquim Barbosa
}

\author{
Evandra Grigoletto* \\ Fabiele Stockmans de Nardi"
}

\section{Resumo}

O presente artigo trata do processo de construção, pela imprensa escrita, de Joaquim Barbosa como herói, durante, sobretudo, sua atuação enquanto ministro do Supremo Tribunal Federal no processo de julgamento do mensalão. Serviram como corpus de análise discursos sobre ele, veiculados na Revista Veja, no portal de notícias do Yahoo e nas redes sociais. Tomando como referencial teórico a Análise do Discurso de linha pecheuxtiana, observamos que a mídia tem um papel relevante nessa construção, ao interpelar os sujeitos leitores a se identificar com essa figura, modelo de identificação, ainda que ela possa ser apenas momentânea. Então, a construção de Joaquim Barbosa como herói e dos sentidos associados a ele como evidentes revelam um trabalho da ideologia que regula a visibilidade/ invisibilidade de determinados atores sociais e dos dizeres que os legitimam.

Palavras-chave: Joaquim Barbosa. Discurso midiático. Herói. Identificação.

\section{Sobre o herói: palavras iniciais}

No universo das redes sociais, da urgência da informação, das novas tecnologias, em que notas, fatos e comentários se espalham velozmente pela rede, alguns fenômenos chamam nossa atenção. Entre eles está a fabricação de novos heróis, que aparecem, quase por um passe de mágica, como os modelos de identificação do momento. E entre esses heróis pode haver os instantâneos, rapidamente projetados ao estrelato e também rapidamente jogados ao esquecimento. Não

\footnotetext{
Professora (adjunto III) do Programa de Pós-Graduação em de Letras da Universidade Federal de Pernambuco. Doutora em Letras pela Universidade Federal do Rio Grande do Sul.

** Professora (Adjunto II) do Programa de Pós-Graduação em de Letras da Universidade Federal de Pernambuco. Doutora em Letras pela Universidade Federal do Rio Grande do Sul.
}

Data de submissão: mar. 2015 - Data de aceite: maio 2015 http://dx.doi.org/10.5335/rdes.v11i1.4986 
nos iludamos, no entanto, com o jogo da instantaneidade, porque a construção dessa heroicidade, do modelo, em alguns casos, vem urdida em uma longa rede de discursos que dão sustentação ao surgimento desse herói, que acaba aparecendo como o modelo ideal e natural com que pode o sujeito se identificar. Mas de que falamos ao nos reportarmos ao herói?

Neste trabalho, retomamos discussões vinculadas a um projeto mais amplo $^{1}$, no qual elegemos pensar a questão do sujeito heroico de nossa época, mais especificamente, o modo como o imaginário social produz e resgata determinados atores sociais para transformá-los ou legitimá-los como heróis. Tomamos como ponto de partida reflexões, ainda em elaboração, acerca da compreensão dessa figura. Resumidamente, podemos apontar alguns traços a partir dos quais temos trabalhado, iniciando pelo que se entende por herói tradicional, ou seja, aquele que, como partícipe do universo cotidiano, em determinado momento de sua existência, sai para viver uma aventura. Ele é alçado à condição de herói porque retorna, como o vencedor, para compartilhar com os seus os resultados de sua vitória. Ao trabalhar com esse herói tradicional, Postal (2012) comenta que essa estrutura, em que ocorre o afastamento, a prova e o retorno, serve como iniciação do sujeito em uma nova etapa de sua vida (psíquica, social, sexual), saindo ele de uma condição "infantil” para pertencer efetivamente aos seus. Desse modo, produz-se um processo de assunção de uma identidade que estaria garantida pela jornada e por aquilo que dela o herói traz consigo.

Se lida pelo viés da psicologia, essa jornada do herói pode ser entendida como um caminho do indivíduo rumo a si mesmo, podendo ser entendida como parte de um processo de subjetivação. Arriscamo-nos a pensar que, num deslocamento de uma visão individualista, tal processo pode nos remeter à construção de um lugar no mundo e, poderíamos dizer, de um lugar de enunciação. Se deslocarmos o olhar que, nessas reflexões, está centrado no indivíduo, afastando-nos da tentativa de "garantir a unidade do sujeito em algum nível de representação" (ZOPPI-FONTANA, 2005, p. 116). Podemos pensar, então, que a figura do herói e sua jornada nos ajudam a refletir sobre a construção do efeito sujeito, enquanto produto de determinações históricas e ideológicas que constroem para esse sujeito um lugar no interior do discurso, um lugar social que ele passa a ocupar e que marca o seu dizer (DE NARDI, 2011).

No entanto, ainda que seja importante para nossa reflexão observar o que sobre o herói já se disse, é efetivamente para a função exercida por essa figura heroica que nos voltaremos, uma vez que, ainda que desapareça a possibilidade de que, em nossa sociedade dita globalizada, encontremos esse herói tradicional, há algo de sua função que permanece, uma vez que funciona como um lugar de identificação para os sujeitos que, ao elencar atitudes e dizeres do/ sobre o herói, constrói com esse conjunto perspectivas discursivas sobre si mesmo. 
Assim, ainda que a figura heroica tenha perdido sua inteireza, tenha se esvaziado de sua epicidade, o espaço heroico, como possibilidade de identificação, pode ser pensado como um lugar no discurso que é ocupado por atores sociais elevados à condição de promulgadores de exemplo comportamental. Nos diferentes olhares que se colocam sobre o herói, o que aparece como recorrência é o fato de ser ele uma fonte perene de identificações imaginárias e de identidade coletiva, desde as antigas epopeias, quando se estabelece sua ligação estreita com o mito nacional, até a contemporaneidade, quando ele assume aspectos peculiares em representações culturais fortemente mediadas pelos discursos midiáticos, com sua propensão à espetacularização.

Partindo, então, desse entendimento sobre a figura heroica é que pretendemos refletir, neste trabalho, sobre o processo de (des)construção do ex-ministro do STF como herói. Para tanto, iniciamos discutindo, teoricamente, a relação entre figuras heroicas, identificação e resistência e, em seguida, faremos algumas análises de discursos que circularam na mídia de um modo geral, incluindo as redes sociais, sobre Joaquim Barbosa.

\section{Figuras heroicas, identificação e resistência}

O que está em causa quando pensamos a criação de heróis em nosso tempo é, portanto, a construção de um espaço, no discurso, a partir do qual se fala so- bre o herói, bem como as possibilidades de identificação com esse lugar que ele representa. Cabe, no entanto, pensarmos que tanto a constituição do sujeito heroico, quanto as possibilidades de identificação com ele só podem ser analisadas, portanto, se tomamos o sujeito como

[...] fruto de múltiplas identificações imaginárias e/ou simbólicas - com traços do outro que, como fios que se tecem e se entrecruzam para formar outros fios, vão se entrelaçando e construindo a rede complexa e híbrida do inconsciente e, portanto, da subjetividade (CORACINI, 2003, p. 203).

Trata-se de pensar que estamos diante de um sujeito da falta que, enquanto propulsora do desejo, permite-nos entender a identidade como um tema em eterno retorno, conceito que opera, segundo Hall (2000, p. 15), “'sob rasura', no intervalo entre a inversão e a emergência".

Como movimento na história, tal qual a designa Orlandi (2002, p. 235), a identidade é, na $\mathrm{AD}$, o resultado, sempre provisório, de constantes processos de identificação, que "são da ordem do simbólico, do social e do político, no modo como são praticados na história, com suas causas e consequências". Não há, portanto, uma identidade para o sujeito, que se move sempre entre identidades que lhe aparecem como provisórias, entre lugares cada vez mais instáveis e complexos, assim como são complexas as sociedades e as relações que nelas se produzem. Lidamos com um sujeito descentrado, dividido, distante do sujeito cartesiano do qual, no entanto, restam vestígios nas 
instituições e na estrutura de poder da modernidade (CORACINI, 2003).

Essa afirmação da autora nos mostra que, apesar de dividido, fragmentado, o sujeito não estará livre das amarras da ideologia, isto é, das relações de poder e força que são inerentes às estruturas da sociedade - e é justamente no seio dessas relações que se produzem as figuras heroicas que nos têm interessado, assim como é no interior dessa luta que são criados os vilões, aqueles a quem é preciso se opor. Ou seja, se, por um lado, as relações de poder e força contribuem para a construção de heróis - instantâneos ou não - como lugares com os quais os sujeitos devem se identificar, por outro, elas também contribuem para o seu esfacelamento, para o seu apagamento. E, nesse jogo entre visibilidade/ invisibilidade, constroem-se não só os heróis, mas também os vilões, que representam tudo o que da sociedade se quer expurgar. Assim, alçar um ator social à posição de herói é colocá-lo no centro de um processo discursivo como aquele que cristaliza, em sua própria constituição, uma forma-conteúdo que é modelar, ainda que possa sofrer deslocamentos e atualizações ao longo do tempo.

Ao olhar para o herói, o que pretendemos compreender, portanto, é a relação entre os sujeitos e os modelos identitários disponíveis na cultura, que os interpelam, propondo/impondo-lhes a adesão a códigos, características e valores. Tal conjunto, intrínseco ao modelo, acena como um lugar simbólico que, ao ser aderido, oferta uma pertença, uma ética, uma estética, uma promessa de "ser".

Importa ressaltar, no entanto, que o sujeito sempre pode resistir, uma vez que não há ritual sem falhas (PÊCHEUX, 1975) e não há poder sem resistência (FOUCAULT, 1979). Ou seja, nos discursos em análise é possível perceber movimentos de resistência do/sobre o sujeito heroico.

Ao falar sobre a resistência, Orlandi (2012, p. 230) vai olhá-la a partir de suas vinculações tanto à forma-sujeito-histórica quanto com a identificação do sujeito com uma formação discursiva (FD), para afirmar que é justamente quando "o sujeito individua(liz)ado se identifica que pode haver ruptura". A resistência emerge nas falhas do ritual, mas a ideologia não cessa de operar, e é por isso que a Pêcheux (2011, p. 114) interessa a "luta de deslocamento ideológica”, ou seja, essa possibilidade de pensar, a partir do funcionamento da ideologia, que ela é antes de tudo um local de

[...] resistência múltipla. Um local no qual surge o imprevisível contínuo, porque cada ritual ideológico continuamente se depara com rejeições e atos falhos de todos os tipos, que interrompem a perpetuação das reproduções (PÊCHEUX, 2011, p. 115).

Como nos ensina Pêcheux (2011, p. 119), "não existe um 'Jogo de todos os jogos", porque os sujeitos se movem em seus pontos de assujeitamento e, portanto, moventes são os lugares a partir dos quais é possível enunciar. Como consequência, o sujeito se constitui a partir de incessantes movimentos de identifi- 
cação, marcados pela heterogeneidade que é característica de toda tomada de posição no discurso, já que não pode dizer de qualquer lugar; processo que, no entanto, comporta uma série de espaços de resistência.

Os espaços de resistência que vão reorganizando e desestabilizando esses movimentos de identificação só podem ser pensados a partir dos processos discursivos, nos quais as relações de força e poder são colocadas em jogo, caracterizando as condições de (re)produção e circulação dos discursos. Então, é, no/pelo discurso, tomado como ponto de encontro entre o real da língua e o real da história, com o equívoco e a contradição que lhes são inerentes, que podemos pensar o herói, sua constituição e atualização (ou o seu possível esfacelamento). Logo, é no intervalo entre a identificação e a resistência que podemos observar o funcionamento da figura heroica, já que o herói tanto pode ser construído como lugar de resistência, como se pode resistir a esse lugar, rechaçando a figura do herói. Tais movimentos, como veremos nas análises a seguir, presentificam-se nos discursos dos mais diferentes espaços midiáticos, os quais produzem visibilidade para sujeitos supostamente invisíveis e vice-versa. É preciso, portanto, olhar para o herói e seus reversos, bem como para os espaços discursivos nos quais haja ou não a possibilidade de heroicização.

\section{Nas redes do mensalão, os discursos sobre Joaquim Barbosa}

No segundo semestre de 2012, o Brasil praticamente parou para assistir, em rede nacional, à transmissão do anunciado julgamento do Mensalão². $\mathrm{O}$ amplo espaço dado pela mídia ao caso e sua consequente espetacularização produziram um fenômeno interessante do qual recortamos apenas um fragmento: a construção de um novo herói nacional, o então ministro do Supremo Tribunal Federal (STF), Joaquim Barbosa. A forte presença de Barbosa na rede tornou-se notícia, como no texto de Flávia Pierry, da Agência O Globo, publicado no portal Yahoo Notícias, com o título Joaquim Barbosa é o "justiceiro" do mensalão nas redes sociais. O texto vinha precedido da imagem que segue:

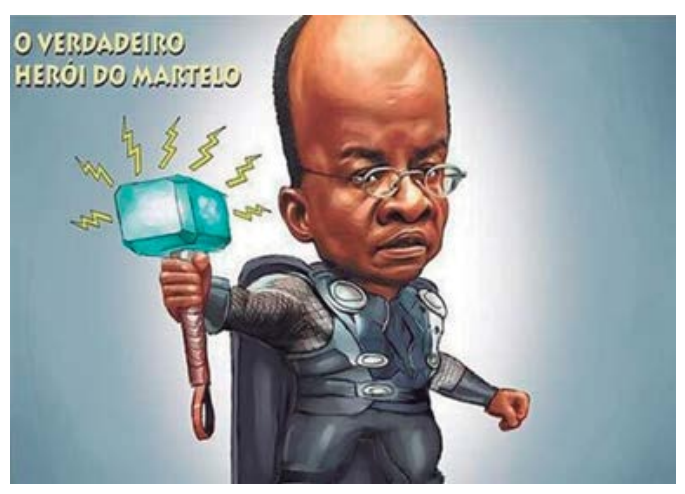

Joaquim Barbosa retratado como Thor, em montagem feita por usuários das redes sociais. (Foto: Reprodução) 
Nela, a imagem de Joaquim Barbosa vem colada à figura de Thor, o deus da mitologia nórdica. O martelo, que era símbolo da personagem mitológica e de suas vitórias nas disputas pelo poder, remete aqui ao ato decisório do juiz, que, ao "bater o martelo", faz valer sua autoridade, que está representada pelo que, na imagem, remete à inteligência e à lucidez de Joaquim Barbosa. Enquanto o poder do herói nórdico estava associado a sua força física, Barbosa se impõe como "O verdadeiro herói do martelo" ao mostrar-se iluminado pela consciência de justiça que se lhe atribui, transposta para a imagem pela fronte iluminada e pela luz que irradia seu martelo.

A vinculação da imagem do Ministro do STF a figuras de heróis consagrados pela mitologia ou pelas histórias em quadrinhos foi uma constante nas redes sociais, especialmente no período de agosto a dezembro de 2012, reproduzindo sentidos que circularam na mídia, durante o julgamento do mensalão. $\mathrm{O}$ julgamento, como o estamos entendendo, vai repercutir no cenário nacional como o ápice de um acontecimento histórico ${ }^{3}$ que veio a público com as denúncias feitas por Roberto Jeferson em junho de 2005. Desde então, foi-se construindo uma memória discursiva em torno desse acontecimento, por meio da circulação de discursos que colocam em jogo relações de força que procuram estabelecer um sentido para esse evento, apagando justamente a sua produção como fato de discurso: apaga-se sua historicidade e o mensalão aparece, então, como uma verdade inquestionável, um dado $^{4} \mathrm{de}$ realidade.

Em torno desse dado se construiu um efeito de verdade que ressoou em diferentes discursos produzidos ao longo do tempo sobre esse acontecimento, resultando como sentido dominante uma busca pela justiça que foi se personificando na figura de Joaquim Barbosa. A vinculação desse sentido ao Ministro não se fez, no entanto, como algo casual ou espontâneo; a sua construção como o "O verdadeiro herói do martelo" foi gestada pelos discursos sobre o mensalão. Exemplo disso é o que se vê na edição da Revista Veja, de setembro de 2007:

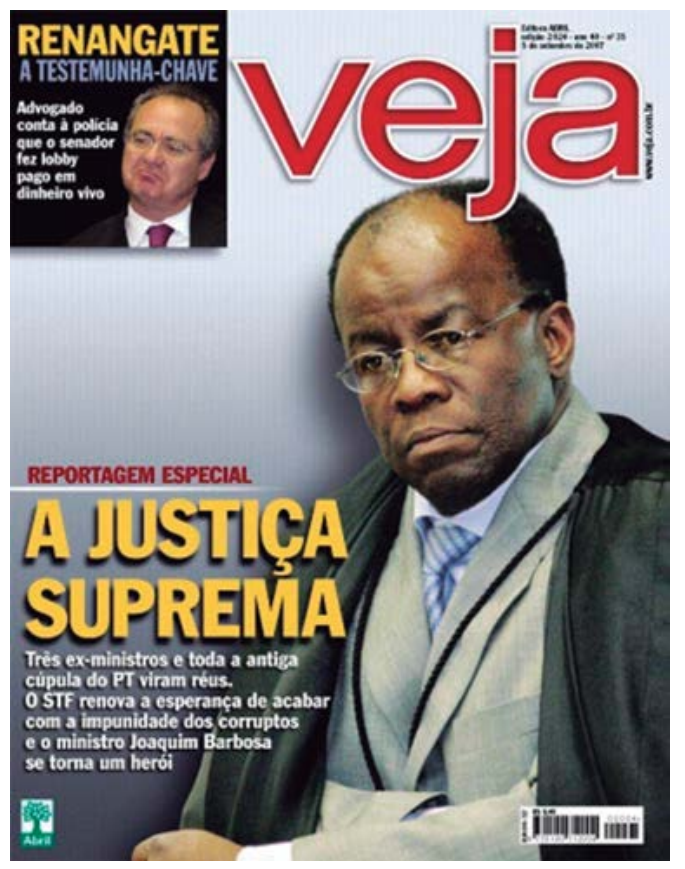

(Disponível em: http://veja.abril.com.br/acervo/home.aspx. Edição 2024, de 05 de setembro de 2007) 
Na Reportagem Especial, intitulada A Justiça Suprema, Joaquim Barbosa aparece como o herói anunciado, aquele que "renova a esperança de acabar com a impunidade dos corruptos". Para a reportagem que apresenta o Ministro do STF, o título escolhido foi $O$ Brasil nunca teve um ministro como ele, reforçando o sentido presente na capa, de que Joaquim Barbosa inaugura uma nova era da justiça brasileira. Se não era então conhecido e popular, o ministro Barbosa passava, agora, a ser apresentado aos brasileiros como o seu herói, aquele que lhes poderia dar a resposta desejada: a condenação dos corruptos. A condenação vinha, então, anunciada, e já estava dita muito antes de seu voto ser lido. E o que se espera do herói senão que ele nos salve das injustiças...

O tom dessa reportagem especial é dado no enunciado abaixo que a precede:

SD1 - No julgamento histórico em que o STF pôs os mensaleiros (e o governo e o PT) no banco dos réus, Joaquim Barbosa foi a estrela - ele, o brasileiro que fala alemão, o mineiro que dança forró, o juiz que adora história e ternos de Los Angeles e Paris. (Disponível em: http://veja.abril.com.br/ acervo/home.aspx. Edição 2024, de 05 de setembro de 2007)

Nesse enunciado se justifica o fato de a revista declarar a inexistência de outro ministro igual a Barbosa em nosso país: Joaquim Barbosa não é um brasileiro qualquer, fala alemão; apesar de ser mineiro, dança forró; e se não bastasse gostar de história, compra ternos em Los Angeles e Paris. A ausência de paralelismo semântico entre as características do
Ministro destacadas pelo jornalista, em sua aparente incoerência, produz como efeito justamente a possibilidade de que se reúnam, em uma só figura, todas as qualidades de um verdadeiro herói brasileiro: conseguiu vencer na vida por seus próprios esforços, não faz alarde de sua competência ou defende causas próprias, não incorpora os defeitos que costumam nos atribuir.

Ao afirmar que o Ministro foi $a$ estrela de um julgamento histórico, a revista ratifica a construção de Joaquim Barbosa como herói, alçando-o a um lugar de resistência aos esquemas de corrupção que assolam o nosso País. Nesse jogo entre (in)visibilidade, a mídia constrói uma imagem de Joaquim Barbosa colada a de um herói. A justificativa para o julgamento ser considerado histórico é a interessante presença - entre parênteses - do fragmento "e o governo e o PT", por meio do qual o governo e o PT são colocados no banco dos réus. Os parênteses, nesse caso, não funcionam como um adendo, ou uma explicação ao texto, sugerem, sim, o efeito de sentido de que o governo, ou melhor, o PT é o principal responsável pelo esquema de corrupção que ficou conhecido como mensalão. Ainda é interessante observar a conjunção aditiva "e" que se repete, sugerindo um movimento de construção de identidade entre mensaleiros-governo-PT -, no qual o governo e o PT e, consequentemente, $\mathrm{o}$ então presidente Lula são os verdadeiros antagonistas a quem é preciso combater. Ao longo da reportagem, como veremos 
mais adiante, constrói-se um interessante jogo que sugere a comparação dos atributos do Presidente da República com os atributos do Presidente do Supremo Tribunal Federal. Ambos vieram de família humilde, mas o caminho percorrido para se chegar ao lugar que ocupa(ra)m foi bem diverso.

Vejamos como funciona esse discurso de enaltecimento do Ministro no interior da matéria:

SD2 - O regente dessa orquestra é um ministro que parece ser tudo o que não é e, no entanto, é tudo o que não parece ser. É um homem frugal, do tipo que prepara seu próprio café-da-manhã, consome comida natural, bebe suco de clorofila, aprecia um chope com os amigos e escuta MPB. Mas também é um sujeito refinado, aficionado por música clássica, modesto bebedor de vinho, que compra seus ternos elegantes em duas cidades: Paris (...) e Los Angeles (...). Joaquim Barbosa também é um homem descontraído, que gosta de jogar uma pelada com amigos duas vezes por semana, aprecia andar pela Lapa, no Rio de Janeiro, e tem prazer em dançar. Ao mesmo tempo, é formal, não permite muita aproximação nem intimidade. É um magistrado apaixonado por história, um brasileiro que fala alemão e detesta o "jeitinho", um mineiro que dança forró (Disponível em: http://veja.abril. com.br/acervo/home.aspx. Edição 2024, de 05 de setembro de 2007).

Em SD2, a referência a Joaquim Barbosa (JB) como a estrela do julgamento, que aparece na sequência anterior, situando-nos no espaço do espetáculo, é retomada quando o ministro passa a ser designado "O regente dessa orquestra". A sua súbita notoriedade, que aparecerá em SD3, como a define a revista, não é tão súbita assim, já que vai sendo tecida nesses discursos midiáticos que o colocam como o centro do espetáculo: aquele que o comanda e que se apresenta como seu personagem central. Esses dizeres sobre o ministro e sua construção enquanto figura pública antecipam sentidos que vão se repetir, em 2012, nas redes sociais: JB é o herói de uma história contada com todos os requintes do espetáculo. Das biografias construídas para seus personagens à edição das imagens a serem transmitidas, tudo que se produziu na grande mídia brasileira sobre o mensalão se fez nos moldes dos grandes espetáculos. Nesse processo, a figura de JB não deixou nunca de estar no centro das atenções, configurando-se como a personagem heroica dessa narrativa. Conforme mencionamos anteriormente, essa personagem representa uma forma-conteúdo que é modelar, à qual os sujeitos aderem. Essa forma-conteúdo se constrói como um lugar simbólico que oferece-impõe ao sujeito códigos e valores a serem seguidos: esse herói é aquele que representa o que o cidadão comum deseja ser, daí sua notoriedade.

Ainda em SD2, merece destaque o interessante jogo entre o ser e a aparência: "parece ser tudo o que não é e, no entanto, é tudo o que não parece ser", diz a Revista, produzindo antecipações sobre a imagem que julga/deseja que o leitor tenha sobre o Ministro. Que discursos sustentam esse jogo entre o ser e a aparência?

Por um mecanismo do funcionamento ideológico, ao aludir a esse jogo, a revista 
produz um sentido que reforça saberes cristalizados no senso comum, por um lado, sobre o que é e quem pode ser um ministro do STF. Por outro, ao fazê-lo, também deixa ver quem são aqueles que não podem ocupar esse lugar social. Se ele parece ser tudo o que não é, o que ele parece ser segundo o discurso da revista?

Embora não explicite verbalmente a questão racial - apagamento que por si só já é bastante significativo -, o recurso à "aparência" que faz a revista coloca em confronto o verbal e o imagético: o primeiro silencia sobre a negritude do ministro; o segundo faz ver o que sua imagem não pode esconder: a cor da pele. Mas o que, para a revista, deveria ser um homem negro? Onde está a contradição entre o que ele parece e o que ele é? Se é negro não pode ser ministro? Se tem hábitos frugais e gosta de MPB não pode ser refinado? Se é brasileiro não pode falar alemão? Se é mineiro não dança forró?

Interessante perceber que o que é aparentemente uma incoerência coloca-nos justamente no lugar da contradição, a qual se produz pelo jogo entre o que, no fio do discurso, deve ser visível e o que se pretende apagar. $\mathrm{O}$ movimento entre visibilidade e invisibilidade pode ser percebido na própria organização sintática do texto, a partir da inserção de estruturas adversativas que privilegiam sempre o que é alçado à condição de essencial para ocupar o lugar social de um ministro (Mas também é um sujeito refinado, aficionado por música clássica, modesto bebedor de vinho, que compra seus ternos elegantes em duas cidades: Paris (...) e Los Angeles). Entendemos que é significativo, portanto, observar que todos os dizeres que reafirmam a brasilidade do ministro e sua apresentação como um homem comum aparecem seguidos dessas construções adversativas, cujo efeito de sentido remete a uma brasilidade polida, sobre a qual se lança um toque nada sutil de refinamento, de quem gosta mesmo do hemisfério norte: "Mas ele gosta mesmo é do Hemisfério

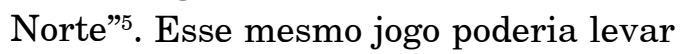
a construções parafrásticas, a partir de repetições observadas na mídia sobre JB: nasceu pobre, mas estudou tanto a ponto de falar uma língua cujo domínio é para poucos; esforçou-se, venceu na vida, mas nunca fez alarde disso; é negro, conhece os problemas dos negros, mas não é militante da negritude. Tudo isso lhe faz um brasileiro exemplar, vencedor, culto e discreto, ou seja, pode ser um magistrado, mas não um magistrado qualquer: "É um magistrado apaixonado por história, um brasileiro que fala alemão e detesta o "jeitinho", um mineiro que dança forró." Sobretudo, pode ser o herói de que os brasileiros precisam, exemplo de cidadão com o qual qualquer um deveria se identificar.

Como já mencionamos, ao trabalhar a construção da imagem de Joaquim Barbosa, a Revista Veja constrói uma comparação quase termo a termo entre ele e Lula. Sem mencionar a edição especial de 2012, e restringindo-nos apenas à 
reportagem de 2007, podemos destacar sequências como: "Eleitor de Lula, Joaquim Barbosa trata sua trajetória de vida de maneira mais reservada do que o presidente. Ele não desfralda sua origem pobre de primogênito de oito filhos de pai pedreiro e mãe dona de casa como bandeira para valorizar sua trajetória de sucesso ou apresentar-se como pós-graduado em povo - e faz questão de valorizar os estudos. " ou "Desmitificador, diz que nunca comeu o pão que o diabo amassou para chegar aonde está e que tudo o que fez foi estudar." Ao afirmar que JB "não desfralda sua origem pobre", o discurso da Veja, pelo funcionamento do operador de negação, diz que Lula faz isso. Logo, constrói-se, pela repetição de alguns elementos no fio do discurso, um efeito ideológico que enaltece, enobrece e dá visibilidade à figura do Presidente do STF e, ao mesmo tempo, desqualifica e produz o apagamento da figura do Presidente da República. Apaga-se, por exemplo, o fato de que foi o Presidente Lula quem indicou Joaquim Barbosa para ser ministro do STF.

O que observamos, ao analisar o que se reproduz nas redes sociais, é que fragmentos desse discurso sobre a figura de JB vão sendo reatualizados, em 2012, durante o julgamento do mensalão, reforçando a construção do ministro como o herói dessa história. Isso se dá, por exemplo, a partir da colagem da figura de Barbosa a diferentes heróis de histórias em quadrinhos, como Batman e o Super Homem. Dos muitos discursos que circulam, sobretudo nas redes sociais, atribuindo a Barbosa essa imagem de herói, recortamos um que entendemos ser representativo desse funcionamento. Trata-se da representação de Barbosa como o Batman do mensalão:

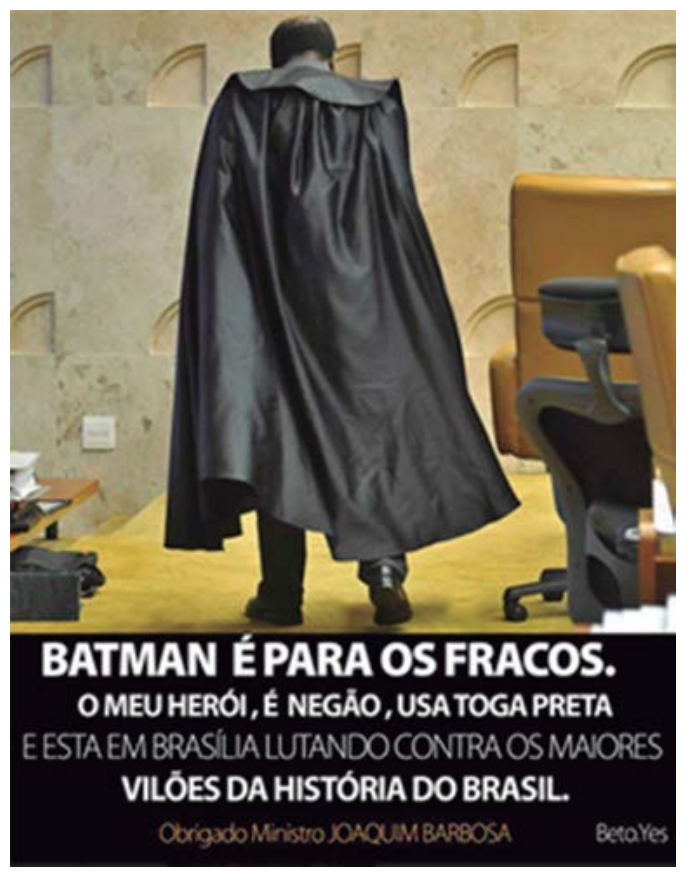

A imagem, em que a toga preta esvoaçante permite a remissão à figura do Batman, vem acompanhada do enunciado "Batman é para os fracos. O meu herói, é negão, usa toga preta e está em Brasília lutando contra os maiores vilões da história do Brasil". Num jogo entre o verbal e o não verbal, produz-se como efeito de sentido dominante a imagem de JB como um herói que supera o próprio personagem de quadrinhos a que sua imagem está vinculada: se Batman, o cavaleiro das trevas, vai salvar 
a sua cidade de vilões obscuros, JB luta contra o poder instituído assumindo o papel de grande justiceiro das massas descontentes; se o alter ego de Batman é um empresário branco e rico que luta contra o crime motivado pelo desejo de vingar os pais mortos na infância, JB é "negão", era menino pobre, conquistou tudo o que tem por meio do estudo e não precisa de identidade secreta para lutar "contra os maiores vilões da história do Brasil". Como Batman, ele não tem super poderes, e é sua formação acadêmica, a reconhecida capacidade intelectual e a posição conquistada por merecimento suas armas nessa guerra contra o crime. Importa lembrar que esse efeito de sentido é recorrente na mídia nos discursos sobre JB, como destacamos nas análises anteriores, em que também o que se destaca de sua figura é a sua capacidade e isenção para julgar. Como podemos observar na SD3, a compensação para o escândalo do mensalão é o fato de o Brasil jamais ter tido "um ministro como Joaquim Barbosa”.

SD3 - O julgamento da semana passada deu a Joaquim Barbosa uma súbita notoriedade. Normalmente, seu e-mail público (gabminjoaquim@stf.gov.br) não recebe mais do que cinco mensagens por semana. Nos últimos dias, passaram de 100. "Em geral, eram mensagem de pessoas se dizendo aliviadas com o resultado do julgamento", conta. Aposentando-se aos 70 anos, como manda a lei, Joaquim Barbosa ficará no tribunal até 2025 - mas ele dá sinais de que talvez os apelos da vida o arranquem dali antes disso. "Com certeza, fico até chegar a minha vez de ser presidente.” Pelo rodízio do tribunal, sua oportunidade chegará dentro de pouco mais de cinco anos. Até lá, haverá um ministro Joaquim Barbosa, encarregado do processo do mensalão. Depois, sabe-se lá. "Gosto da vida", diz ele. E, bem ao seu estilo globalizado, percorre mentalmente seus bairros preferidos em Paris, Berlim e Rio, e completa: "Gosto do Marais, gosto de Prenzlauerberg, gosto da Lapa”. O Brasil jamais teve um deplorável escândalo como o mensalão. Como compensação, também jamais teve um ministro como Joaquim Barbosa (Disponível em: http://veja.abril.com.br/acervo/home.aspx. Edição 2024, de 05 de setembro de 2007).

Embora SD3 tenha sido produzida em 2007, cinco anos antes do julgamento final do mensalão que ocorreu em 2012, ano em que se populariza a figura de JB como herói, os sentidos vão numa mesma direção, apontando para uma regularidade em termos de funcionamento discursivo.

Tal funcionamento aponta para a edificação, pelo discurso, de um herói capaz de salvar a todos dos vilões que nos ameaçam, apagando-se as contradições que envolvem os dizeres sobre esse acontecimento histórico e, também, nesse caso, sobre a história do Brasil, que se divide, então, entre heróis e vilões. Nesse mundo em que é preciso escolher entre estar do lado do bem ou do lado do mal, o herói aparece como a única figura possível com que se identificar, já que em suas mãos está a justiça e em suas palavras a verdade.

E a súdita notoriedade, uma das características que justifica o fato de Joaquim Barbosa ter sido alçado à condição de herói, mantém-se, sobretudo no discurso da Veja. Vejamos alguns recortes da reportagem de capa da edição de 
junho de 2014, quando ele deixa a presidência do Supremo Tribunal Federal. Eis a capa da revista:

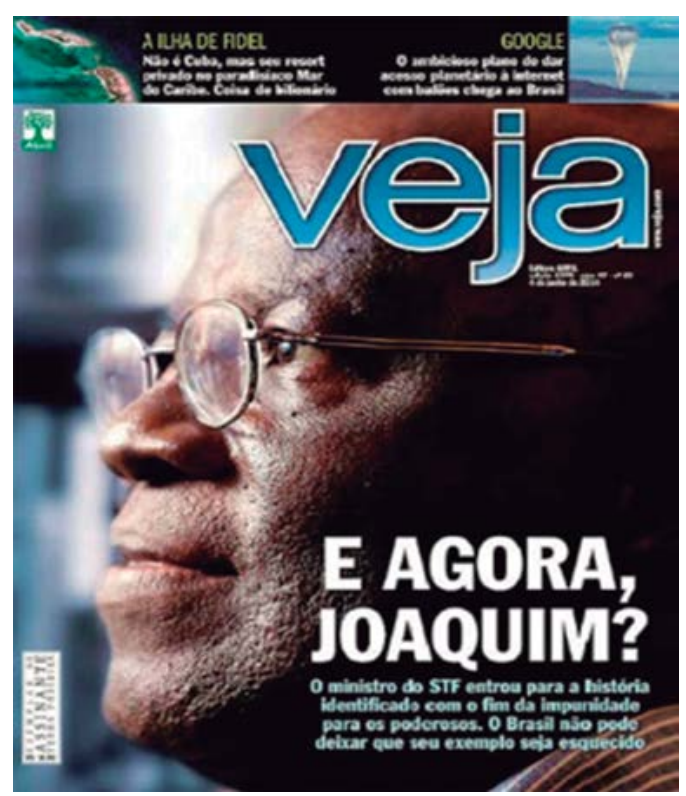

(Disponível em: http://veja.abril.com.br/acervo/home.aspx. Edição 2376, de 04 de junho de 2014)

Nesta reportagem de capa da Veja, dedicada mais uma vez a Joaquim Barbosa, o assunto em pauta é a sua aposentadoria, a qual, segundo a revista, foi antecipada, devido a derrotas que o Ministro vinha enfrentando nas votações do STF. Daí a pergunta retórica que dá título à reportagem - $\mathbf{E}$ agora, Joaquim?. Mais do que se dirigir ao ministro, questionando-o sobre o que fará após sua aposentadoria, essa questão interpela os leitores a se identificar com a imagem estampada, mas também projetada da figura de Joaquim Barbosa. Uma figura que entrou para a história, porque colocou fim à impunidade dos poderosos.
Um exemplo de homem, de cidadão ético, de profissional que o povo brasileiro não pode esquecer. Interessante perceber ai também a relação de intertextualidade com o poema "E agora, José?", de Carlos Drummond de Andrade. No entanto, ao contrário do personagem fictício - José -, citado no poema de Drummond como um possível representante de muitos brasileiros sofredores, sem rumo nem destino, Joaquim aqui remete a essa figura especial, exemplo de caráter e retidão, que construiu o seu nome por mérito, afastando-se do destino de muitos outros joaquins brasileiros, pobres e negros. Então, importa mais o que Joaquim Barbosa fez ao longo de sua trajetória até aqui, a qual é novamente destacada pela Veja, do que o que ele fará, num futuro próximo ou distante. Num jogo entre passado e futuro, entre visibilidade e invisibilidade, o que ganha destaque é o passado e a notoriedade conquistada por JB. A sua trajetória não poderá ser apagada, afinal

Anunciadas as penas e decretadas as prisões, Barbosa se tornou uma espécie de herói nacional, o cavaleiro vingador $\mathrm{da}$ capa preta, aplaudido nas ruas e assediado para disputar as eleições (VEJA. Disponível em: http://veja.abril.com.br/acervo/home. aspx. Edição 2376, de 04 de junho de 2014).

O herói, portanto, está legitimado pelo povo brasileiro. O que o discurso da Veja apaga, no entanto, é que esse título de herói nacional é fruto da construção do próprio discurso midiático. Tamanha foi a visibilidade dada pela mídia ao Ministro, tamanha foi a repetição de dizeres elogiosos que um sentido fixou-se como o 
verdadeiro acerca de Joaquim Barbosa: o herói que veio salvar os "brasileiros do bem" das mazelas, dos esquemas de corrupção provocados pelos "brasileiros do mal". Como já referimos anteriormente, pelo funcionamento ideológico, apagam-se as contradições, os sentidos outros e nega-se qualquer possibilidade de algum brasileiro não se identificar com esse homem exemplar.

Portanto, o Brasil não só não pode deixar que seu exemplo seja esquecido, como é um País que precisa de exemplos como o de Joaquim Barbosa. Observemos a sequência abaixo, que inicia a reportagem sobre o Ministro.

SD4: O BRASIL PRECISA DE EXEMPLOS. O legado do ministro Joaquim Barbosa transcende a prisão de um bando de corruptos poderosos. Ele mostrou que é possível fazer a coisa certa sem precisar transigir ou flertar com o que existe de errado. (Disponível em: http://veja.abril.com.br/acervo/home. aspx. Edição 2376, de 4 de junho de 2014)

Nessa sequência, mais uma vez, os leitores são interpelados a se identificarem com o exemplo de Joaquim Barbosa, pois o seu legado transcende a prisão de um bando de corruptos poderosos. Para justificar tal afirmação, a revista destaca que é possível fazer a coisa certa sem precisar transigir ou flertar com o que existe de errado, fazendo irromper, no fio do discurso, um pré-construído que é da ordem do interdiscurso: para fazer a coisa certa, no Brasil, é preciso transgredir, ser corrupto, usar do jeitinho brasileiro, etc. Com isso, produz-se um efeito de generalização no discurso, remetendo ao sentido de que só é possível, nesse País, fazer a coisa certa por caminhos tortos. E nós sabemos que não é bem assim, que muitos brasileiros fazem a coisa certa, sem passar pelos caminhos tortos, mas que, nem por isso, tornam-se celebridades como Joaquim Barbosa. O que diferencia então Joaquim Barbosa de outros joaquins, de outros brasileiros? Mais do que seus feitos pela Nação Brasileira, no caso do Mensalão, é o fato do discurso da mídia o alçar a essa posição de herói. $\mathrm{E}$ uma vez construída essa imagem, uma vez o sujeito colocado na função heroica, não há como os brasileiros não se identificarem.

\section{Considerações finais}

Esses movimentos de análise aqui realizados sobre a figura de Joaquim Barbosa nos permitem encaminhar algumas reflexões que nos serão necessárias à observação dessa figura do herói ou, mais especificamente, da construção da função heroica no discurso.

Os dizeres sobre JB e o julgamento do mensalão nos levam a entender que a construção da função heroica, quando relacionada a um acontecimento histórico específico, vai sendo gestada a partir da memória discursiva que se delineia em torno desse acontecimento. O herói põe em funcionamento, assim, um movimento pelo qual se vão apagando as contradições acerca desse evento para que sobre ele se produza um efeito de verdade: se o herói é a justiça e o bem, 
tudo o que a ele se opõe deve ser combatido e apagado.

Gestar o herói pelo discurso, portanto, faz emergir um dizer que se assenta sobre dualidades: o bem e o mal, os mocinhos e os bandidos vão sendo ditos e desenhados a partir de uma trama muito bem urdida pela qual o acontecimento histórico pode ser definido antes mesmo de seus momentos finais. Não havia para o mensalão outra possibilidade de julgamento que não a condenação dos culpados por JB, o herói já anunciado de um veredito longamente construído; da mesma forma, parece não haver, para os sujeitos, outra possibilidade que não a de identificação com esse herói, tão pleno de virtudes, tão senhor das suas verdades.

A nova era da justiça brasileira, anunciada pelo título da primeira reportagem que analisamos, vai se repetindo nos dizeres que (re)colocam JB no lugar do herói, atribuindo a esse homem e às suas virtudes a construção de um novo tempo. Um novo tempo que acaba com sua aposentadoria? Não, já que o seu exemplo ficou para a história e deve ser seguido por todos os brasileiros, como anuncia a segunda reportagem analisada. Assim, nesse lugar do herói, o homem é alçado ao lugar de modelo de identificação, ainda que ele possa ser, nesse nosso tempo, apenas momentâneo.

A construção desse herói e dos sentidos associados a ele como evidentes revela um trabalho da ideologia (ZIZEK, 1996) que regula a visibilidade/invisibilidade de determinados atores sociais e dos dizeres que os legitimam. Nessa relação, há um desejo de apagar as contradições inerentes ao processo socio-histórico em que esse herói foi produzido. Colar o herói ao acontecimento histórico que desencadeou seu surgimento é tentar refrear possíveis movimentos de contra/ desidentificação por parte do sujeito com esse lugar de autoridade construído para que o herói o ocupe. Mas é preciso nesse momento acatar a lição de Pêcheux (1990, p. 17) de que "não há ritual sem falha, desmaio ou rachadura", olhando para o funcionamento dos processos discursivos em que esses dizeres circulam para encontrar neles os espaços de resistência, já que "cada ritual ideológico continuamente se depara com rejeições e atos falhos de todos os tipos, que interrompem a perpetuação das reproduções" (PÊCHEUX, 2011, p. 115). Resistências, no entanto, não encontradas no corpus analisado neste artigo. Como anunciava a reportagem da Veja de 2014, "Sorte dos brasileiros do bem, azar do PT". Ou seja, o discurso midiático aqui analisado não deixa brechas para que brasileiros do bem não se identifiquem com esse herói nacional que esse mesmo discurso ajudou a construir e sedimentar. 


\section{The "hero's (de)construction in the speeches regarding The Mensalão Scandal: the case of Joaquim Barbosa}

\begin{abstract}
The present paper focus on the construction process, by the written media, of Joaquim Barbosa as a hero, during, mainly, his acting while Minister of the Supreme Federal Court in the judgment process of the mensalão scandal. Discourses about him propagated in Veja magazine, Yahoo website and social networks were used as our corpus analysis. Having the Discourse Analysis in the light of Pecheux as our theoretical frame, we have observed that media plays a relevant role in that construction, when it interpellates the subject readers to identify themselves with that person, a model of identification, even though he may be a temporary one. Therefore, the construction of Joaquim Barbosa as a hero and the meaning associated to him as evident reveal a work of ideology, which regulates the visibility/invisibility of certain social actors and the sayings that legitimate them.
\end{abstract}

Keywords: Joaquim Barbosa. Media discourse. Hero. Identification.

\section{Notas}

1 Trata-se do projeto Identificação, memória $e$ atualidade nos modos de constituição do "herói", que possui financiamento do Edital Universal do CNPQ (Processo 475893/2013-1)

2 Mensalão é o nome dado ao escândalo de corrupção política mediante compra de votos de parlamentares no Congresso Nacional do Brasil, que ocorreu entre 2005 e 2006 . O caso teve como protagonistas alguns integrantes do governo do então presidente Luiz Inácio Lula da Silva, membros do Partido dos Trabalhadores e de outros partidos, sendo objeto da ação penal de número 470, movida pelo Ministério Público no Supremo Tribunal Federal (Disponível em: http://pt.wikipedia.org/wiki/ Escândalo_do_Mensalão. Acesso em 29 abr. 2015).

3 Estamos tomando aqui o acontecimento histórico, conforme Dorneles (1999, p. 158), que, ao falar sobre a apropriação que a história faz dos acontecimentos, comenta que, "Por essa impossibilidade de ser dito no seu todo, o acontecimento histórico, o evento, em si mesmo, é real. A história não narra o real, mas a realidade é constituída pela/na trama da discursividade. A simbolização do fato vai constitui-lo como algo de aparente estabilidade lógica, desestabilizável pela mudança da posição sujeito interpretante."

4 Orlandi (1996, p. 36) menciona o deslocamento do dado para o fato como a possibilidade, para a $\mathrm{AD}$, "de se trabalhar o processo de produção da linguagem e não apenas seus produtos". Trabalhar com os dados é naturalizar a relação do analista com o seu objeto, apagando o trabalho de interpretação mediante o qual os fatos são produzidos.

5 O enunciado que destacamos aparece na reportagem da Veja que está em análise no momento em que ser faz referências às viagens feitas pelo Ministro, e suas passagens pelo Senegal e pela África do Sul.

\section{Referências}

CORACINI, Maria José (Org.). Identidade \& discurso: (des)construindo subjetividades. Campinas: Unicamp, 2003.

DE NARDI. F. S. Subjetivação na língua do outro: práticas de escrita em blogs para o ensino-aprendizagem de língua espanhola. In: GRIGOLETTO, E. DE NARDI. F. S.; SCHONS, C. R. (Org.). Discursos em rede: práticas de (re)produção, movimentos de resistência e constituição de subjetividades no ciberespaço. Recife: EDUFPE, 2011, p. 227-248. 
DORNELES, E. F. O discurso do MST: um acontecimento na estrutura agrária brasileira. In. INDURSKY, F.; LEANDRO FERREIRA, M. C. Os múltiplos territórios da Análise do Discurso. Porto Alegre: Sagra Luzzatto, 1999. p. 149-172.

FOUCAULT, M.(1979) Microfísica do poder. Organização e Tradução: Roberto Machado. 15. ed. Rio de Janeiro: Edições Graal, 2000.

HALL, S. Quem precisa da identidade? In. SILVA. T. T. da. (Org.) Identidade e diferença. Petrópolis: Vozes, 2000, p. 103-133.

ORLANDI, E. Interpretação: autoria, leitura e efeitos do trabalho simbólico. Petrópolis: Vozes, 1996.

. Língua e conhecimento linguístico: para uma história das ideias no Brasil. São Paulo: Cortez editora, 2002.

Discurso em análise: sujeito, sentido, ideologia. 2. ed. Campinas: Pontes Editores, 2012.

PÊCHEUX, M. (1983). O discurso: estrutura ou acontecimento. 3. ed. Tradução Eni P. Orlandi et al. Campinas: Pontes, 2002.

(1975) Semântica e discurso: uma crítica à afirmação do óbvio. 2. ed. Tradução: Eni P. Orlandi et al. Campinas: Unicamp, 1995.

(1983) Ideologia - aprisionamento ou campo paradoxal? In: PECHEUX, M. Análise de discurso. Textos Escolhidos por Eni Orlandi. 2. ed. Campinas: Pontes, 2011, p. 107-119.

POSTAL, R. Mascarilha e récita: estratégias contemporâneas de figuração identitária. In: SIMPÓSIO NACIONAL DISCURSO, IDENTIDADE E SOCIEDADE: Dilemas e desafios na contemporaneidade, III, Anais... Campinas, 2012. Disponível em: <http://www.iel. unicamp.br/sidis/anais/pdf/POSTAL_RICARDO.pdf>. Acesso em: 13 jan. 2013.

VEJA. Edição 2376, ano 47, n. 23. São Paulo: Editora Abril, 4 jun. 2014.
VEJA. Edição 2024, ano 43, n. 35. São Paulo: Editora Abril, 4 jun. 2007.

ZIZEK, Slavoj. O espectro da ideologia. In: ZIZEK, Slavoj. (Org). Um mapa da ideologia. Tradução de Vera Ribeiro. Rio de Janeiro: Contraponto, 1996. p. 39-50.

ZOPPI-FONTANA, M. G. O outro da personagem: enunciação, exterioridade e discurso. In. BRAIT, B. (Org.) Bakhtin: dialogismo e construção de sentido. Campinas: Ed. da Unicamp, 2005, p. 108-117. 